\title{
Análise do Meio Físico como subsídio à definição de diretrizes em Planos Diretores Municipais no Sul de Minas Gerais
}

\author{
Physical environment analysis as a subsidy for guidelines definitions at municipal plans on the \\ South of Minas Gerais.
}

\begin{abstract}
Clibson Alves dos Santos Professor Dr. do Programa de Pós-Graduação em Geografia - PPGEO UNIFAL MG, Brasil clibson.santos@unifal-mg.edu.br

Caio Faria da Cunha Barbosa Adorno Mestrando Programa de Pós Graduação em Geografia - PPGEO UNIFAL-MG, Brasil caioadorno31@gmail.com

Raphaela A. de Oliveira Araujo Mestranda pelo Programa de Pós-Graduação em Geografia - PPGEO UNIFAL MG, Brasil raphaela.araujo@sou.unifal-mg.edu.br
\end{abstract}

\begin{abstract}
Resumo
$\mathrm{O}$ ordenamento territorial e as transformações paisagísticas ilustram um processo em que a sociedade mantém uma relação de apropriação particular com a natureza. Emerge desta situação a necessidade de se desenvolver diretrizes capazes de subsidiar o crescimento urbano no contexto ambiental. Com bases geossistêmicas, o presente trabalho buscou destacar as características inerentes ao conhecimento do meio físico dos municípios de Cachoeira de Minas, Pouso Alegre e Santa Rita do Sapucaí como alicerce à definição de diretrizes em planos diretores municipais no contexto do Sul de Minas Gerais. A análise das características morfodinâmicas associadas a enchentes e riscos geológicos nos municípios escolhidos exemplificam o padrão de crescimento urbano comumente encontrado no Sul de Minas Gerais, com expansão em fundos de vale e encostas. Foram elaborados documentos cartográficos com bases na ecodinâmica de Jean Tricart (1977) para estabelecer classes de ocupação da paisagem e ilustrar como as diretrizes urbanas devem auxiliar os planos diretores.
\end{abstract}

Palavras-chave: Geomorfologia; ordenamento territorial; enchentes e inundação.

\begin{abstract}
Territorial planning and landscape transformations illustrate a process in which society maintains a relationship of particular appropriation with nature. From this situation emerges the need to develop guidelines capable of subsidizing urban growth in the environmental context. With geosystemic bases, this study sought to highlight the characteristics inherent to the knowledge of the physical environment of the cities of Cachoeira de Minas, Pouso Alegre and Santa Rita do Sapucaí as a foundation for defining guidelines in municipal master plans in the context of Southern Minas Gerais. The analysis of morphodynamic characteristics associated with floods and geological hazards in the chosen cities exemplify the pattern of urban growth commonly found in southern Minas Gerais, with expansion in valley bottoms and slopes. Cartographic documents were elaborated based on Jean Tricart's ecodynamics (1977) to establish classes of occupation of the landscape and illustrate how urban guidelines should support master plans.
\end{abstract}

Keywords: Geomorphology; territorial planning; flood and spate. 


\section{INTRODUÇÃO}

A sociedade segue uma lógica de pensamento onde o seu reflexo é dominante em relação à natureza (NUNES, 2002). Essa concepção de superioridade evidencia a arrogância do ser humano e o faz enxergar os recursos naturais como produto particular (VINHA, 2011). Logo, o interesse em saciar os anseios inerentes à satisfação pessoal prevalece, enquanto, por muito tempo, a preocupação com a temática ambiental é inexistente nesta lógica perversa que determina o desenvolvimento da sociedade.

O processo de transformação da paisagem carrega a concepção de um padrão de desenvolvimento moldado por interesses particulares que comprometem os recursos naturais (SANTOS, 2009). O desejo capitalista e a busca incessante pelo lucro resultam no crescimento econômico das cidades, e não no seu desenvolvimento (NASCIMENTO; CARVALHO, 2005).

É nesse contexto que a articulação das dimensões natural e humana se faz necessária. Ora, se por um lado, a urbanização modifica a paisagem, é de se esperar que neste momento a dinâmica natural do sistema seja modificada (NUNES, 2002). A discussão do planejamento espacial coerente ao discurso da sustentabilidade é carregada por uma série de questões desafiadoras. A análise geográfica da paisagem urbana evidencia a proporção e dimensão da intervenção antrópica sobre o espaço (ROSS, 1990).

A distribuição dos núcleos urbanos na paisagem altera e transforma a dinâmica natural do sistema, logo, reflete nos processos naturais como o escoamento, infiltração e intemperismo (ROSS, 1990). Este cenário realça a necessidade de se estabelecer certo nível organizacional nos componentes do sistema, natural e humano, para execução de um planejamento adequado.

Segundo a Teoria Geral dos Sistemas (TGS), elaborada pelo austríaco Ludwig Von Bertalanffy em 1969, a paisagem é vista como um sistema (MARQUES NETO, 2004). A partir desta teoria, o sistema considerado resulta da interação de suas unidades, e não apenas da soma delas (AMORIM FILHO, 1998). Portanto, uma variação entre qualquer um dos componentes tem o potencial de refletir no sistema todo (CHRISTOFOLETTI, 1999).

Uma análise subsidiada pelo axioma holístico vai considerar o todo como resultante da inter-relação de seus elementos, organizados e hierarquizados (TROPPMAIR; GALINA, 2006). Foi esta visão holística que norteou a Teoria Geral dos Sistemas, que buscou excluir a análise fragmentada por uma análise que fosse capaz de englobar todo o sistema (MONTEIRO, 2001). Christofoletti (1999) afirma que a teoria dos sistemas constitui um campo teorético inovador para as ciências naturais, e passou a considerar uma visão integradora de mundo.

Norteada pela Teoria Geral dos Sistemas emerge na geografia a teoria geossistêmica, com bases soviéticas e francesas (CHRISTOFOLETTI, 1999). A compreensão do meio físico paralela ao 
conhecimento socioeconômico e cultural predominante é imprescindível na busca de soluções para o espaço urbano. Desta maneira é relevante a busca por metodologias capazes de trabalhar o planejamento dos centros urbanos de maneira sistêmica e holista (GUERRA; MARÇAL, 2006).

Antagônicos a este contexto, a maioria dos centros urbanos brasileiros têm se desenvolvido sem o devido conhecimento fisiográfico para o planejamento e gestão territorial (SOUZA, 1999). O reflexo desta situação é visto na expansão desordenada seguida pelo surgimento de adversidades naturais, como a instabilidade de encostas e a ocupação de áreas naturalmente suscetíveis as enchentes e inundações.

Neste contexto de planejamento urbano é preciso ressaltar que o Plano Diretor Municipal é o documento responsável em oferecer diretrizes para o desenvolvimento das cidades. É tido como um mecanismo fundamental no exercício da ordenação territorial (VILLAÇA, 2004), mas que, comumente, desconsidera a heterogeneidade do meio físico e como ela influencia nas questões sociais.

Desta forma, o presente trabalho destacou as principais características fisiográficas dos municípios de Pouso Alegre, Santa Rita do Sapucaí e Cachoeira de Minas com o intuito de subsidiar novas diretrizes municipais do Plano Diretor no contexto regional do sul de Minas Gerais. São cidades que representam a realidade de expansão urbana na área, com o crescimento municipal para áreas de fundo de vale e nas encostas, o que proporciona um cenário naturalmente suscetível a processos geológicos e de enchentes e inundação.

Pouso Alegre e Santa Rita do Sapucaí são municípios que apresentam um histórico de ocorrência de eventos associados a enchentes e inundação. Ilustram a hipótese do crescimento urbano em áreas naturalmente suscetíveis a esses processos, assim como Cachoeira de Minas que, embora não apresente um histórico de ocorrência para esses eventos, tem apresentado padrão de crescimento para o fundo de vale e encostas, ocupando áreas inadequadas. Neste sentido, as diretrizes precisam do conhecimento do meio físico para que as leis de uso e ocupação do solo estejam adequadas à realidade que o município apresenta.

\section{REFERENCIAL TEÓRICO}

\subsection{A teoria Geossistêmica como proposta de análise geoambiental}

A dicotomia que permeia a episteme geográfica é um dos principais obstáculos frente ao exercício da organização do espaço geográfico (NUNES, 2012). O padrão abusivo que prevalece na relação do homem com a natureza resulta numa séria de contradições ambientais nos sistemas naturais (GUERRA; MARÇAL, 2006). 
A compreensão da paisagem como uma totalidade começa com o paradigma holístico na história do pensamento geográfico. Alexander Von Humboldt é conhecido como um dos precursores deste paradigma, que para compreender a paisagem observada pela empiria, destacou a necessidade de realçar a conexão dos componentes existentes nos processos e nas formas (WULF, 2016).

A interação das esferas sociais e ambientais transforma a paisagem, logo, é necessário que surjam teorias e metodologias que ofereçam um escopo teórico-metodológico para a análise integrada do espaço (NUNES, 2014). Na procura de uma abordagem holista da natureza, a geografia soviética, com Sotchava (1976), e francesa, com Bertrand (1972), ambos subsidiados pela Teoria Geral dos Sistemas de Bertalanffy (1969), surgem com a Teoria dos Geossistemas (RODRIGUES, 2001).

$\mathrm{O}$ conceito de geossistema delimita uma proposta de caráter integrador e heterogêneo para o espaço geográfico (MONTEIRO, 2001. CHRISTOFOLETTI, 1999. TROPPMAIR, 2000). A paisagem é compreendida como um sistema aberto, marcada por relação constante dos elementos que a compõem. Assim, as interações e inter-relações resultam na totalidade sistêmica.

A teoria dos geossistemas busca realçar a conexão que existe entre os diversos níveis de organização espacial com os mecanismos que modificam a paisagem. (MONTEIRO, 2001). Essa conexão precisa ser contemplada no planejamento territorial e destacar quem são e como agem os mecanismos, na busca de adequar as ações sociais à dinâmica do quadro natural (MONTEIRO, 2001).

Suertegaray (2005) exemplifica que cada parcela do espaço geográfico precisa ser analisada por uma lente que combine diferentes padrões da paisagem e, que cada vez mais, as tendências atuais exigem que esta lente projete a ação antrópica na esfera natural. $O$ espaço geográfico é diversificado de acordo com as interações, combinações e hierarquia dos componentes que nele coexistem (SUERTEGARAY; MORETTI, 2014). Desta forma, o estudo espacial precisa considerar a totalidade para obter respostas precisas na busca dos planos de ordenação (TROPPMAIR, 2000).

A geografia ganha caráter político e se torna uma ferramenta que se aprimora como veículo de planejamento (NEVES, 2019). A compreensão dos fenômenos sistêmicos e como eles se espacializam é fundamental para o entendimento da paisagem e como ela se dispõe no espaço geográfico (PEREZ FILHO et al., 2008). Os diagnósticos e prognósticos que se debruçam sobre a temática socioambiental e sua organização possuem seus alicerces na episteme geográfica e, mais precisamente, na teoria geossistêmica.

Nesta narrativa, a geografia física, com a teoria geossistêmica, disponibiliza uma possibilidade de análise da paisagem sob a perspectiva holista $\mathrm{O}$ discurso sistêmico de uma visão 
teórico-metodológica vai além do conformismo de que uma análise se torna excludente ao escolher uma área específica da episteme geográfica, comumente a geomorfologia (AB’SABER, 1969).

A complexidade que deve existir em uma abordagem geográfica não é reduzida com a solidez que a analise geossistêmica propõe. A preocupação existe na definição da escala de análise da paisagem. Se cada recorte apresenta características específicas, o processo de interação e compreensão da paisagem parte da análise destas especificidades. A dicotomia presente na episteme geográfica deve ser contemplada no plano teórico-metodológico, desta maneira a redução da complexidade das relações que se espacializam e modificam a paisagem não compromete o exercício da ciência.

\subsection{Ordenamento territorial e Plano Diretor Municipal}

De acordo com Santos (1996) as relações sociais se reproduzem e se materializam no espaço geográfico. Esse processo reflete as necessidades e a cultura do ser humano e precisa ser compreendida como um processo (CORREA, 1989). É nesse momento que a gestão urbana carrega as dimensões sociais, políticas, culturais e ambientais que representam interesses municipais (VILLAÇA, 2001) que buscam desenvolver e projetar a cidade.

O plano diretor, de acordo com o Estatuto da Cidade (2002), reúne normas e diretrizes para orientar e guiar o planejamento urbano (VILLAÇA, 2001). É um documento que precisa contemplar um diagnóstico completo da realidade física, social, econômica, politica, cultural e administrativa de um município.

A atuação do poder público precisa ser acompanhada do conhecimento geocientífico para que a gestão do espaço urbano seja eficiente e atinja um nível satisfatório. A gestão é compreendida como propostas e ações realizadas no presente, enquanto o planejamento está relacionado a ações que almejam o futuro (CASTELLO, 1999). Neste sentido, planejamento e gestão não são propostas avulsas, é na intersecção entre os problemas atuais (gestão) e o prognóstico (planejamento) que o Plano Diretor efetiva sua função de organizar a cidade (VILLAÇA, 2001).

O planejamento urbano busca organizar os diferentes eixos municipais (ambiental, político, socioeconômico e cultural) e providenciar subsídio para a evolução contínua das cidades. Villaça (2004) descreve que as utopias urbanas são calcadas pelas tentativas de unir aspectos naturais em uma paisagem desconfigurada pela ação humana. Nesse momento a análise geossistêmica da paisagem oferece uma alternativa para o planejamento urbano na temática dos problemas de ordem natural, como enchentes e inundações.

É nesta narrativa que se destaca a Lei 12.608 de 2012, que institui a Política Nacional de Proteção e Defesa Civil - PNPDEC. A mesma discorre sobre as obrigações das instituições públicas 
nas diversas escalas para as temáticas de prevenção, preparação e recuperação de cenários de desastres naturais, como deslizes, enchentes e inundações.

O documento do PNPDEC encarrega certas obrigatoriedades dos órgãos públicos em relação ao mapeamento de áreas de risco e de estudos voltados para identificação de áreas vulneráveis e suscetibilidades de ocorrência de eventos desastrosos. Também "dispõe sobre o Sistema Nacional de Proteção e Defesa Civil - SINPDEC e o Conselho Nacional de Proteção e Defesa Civil - COMPDEC" (BRASIL, Lei n 12.608/2012).

O SINPDEC delega a obrigatoriedade dos Estados e da União na prestação de serviços, ajuda financeira e material, aos municípios afetados por desastres naturais que não conseguem arcar com as despesas necessárias. Nesta situação, cabe aos órgãos municipais a criação do Conselho Nacional de Proteção e Defesa Civil para a execução e coordenação do PNPDEC. São obrigações do COMPDEC “auxiliar na formulação, implantação e execução do Plano Nacional de Proteção e Defesa Civil; Propor normas para implantação e execução da PNPDEC; e acompanhar o cumprimento das disposições legais e regulamentares de proteção e defesa civil” (BRASIL, Lei ${ }^{\circ}$ 12.608/2012).

É preciso correlacionar as diretrizes da PNPDEC como complementares ao Plano Diretor no que se aplica ao ordenamento territorial. É responsabilidade da escala municipal a adequação das propostas delimitadas no PD para o uso e ocupação de áreas identificadas como vulneráveis aos processos destacados pelo CONPDEC, como as enchentes e inundações. Essas ações governamentais são essenciais na prevenção de tragédias em regiões atingidas por fenômenos de ordem natural, como os hídricos-climáticos.

A Constituição Federal do Brasil de 1988, artigo 182, traz a obrigatoriedade do Plano Diretor para aqueles municípios com mais de vinte mil habitantes (entre outras especificidades), que reforça a Lei ${ }^{\circ}$ 10.257/2001, conhecida como Estatuto da Cidade, a correlação destas leis com o PNPDEC reforça a ideia do desenvolvimento sustentável.

Esse cenário constitui uma das várias tentativas de ordenar o espaço com normas e diretrizes urbanísticas (SCHWEIGERT, 2007). Neste momento, o conhecimento do meio físico é uma das prioridades do Plano Diretor e, infelizmente, negligenciado em diversas situações. O Estatuto da Cidade confere o equilíbrio ambiental como uma necessidade coletiva associada à qualidade ambiental (SCHWEIGERT, 2007).

Uma das propostas destacadas por Souza (SOUZA; SOBREIRA, 2014) é a elaboração de cartas de aptidão à urbanização frente a esses fenômenos. Os projetos públicos de zoneamento de áreas associadas a desastres naturais, como os conectados a deslizamentos de encostas, movimentos de massas e inundações precisam do conhecimento fisiográfico da área de interesse relacionado aos grupos sociais existentes na mesma (NUNES, 2012). 


\section{METODOLOGIA}

Para que fossem atingidos os objetivos do presente trabalho foram realizados diferentes níveis de análise, sistematizados pelo levantamento bibliográfico e produção do acervo; produção das bases cartográficas; análise e identificação de áreas naturalmente suscetíveis aos processos geológicos, de enchentes e inundações e; por fim; realizada uma síntese das relações entre a ocupação antrópica, a morfogênese e o padrão das formas semelhantes nos municípios estudados.

O levantamento bibliográfico e a produção do acervo consistiram na busca por teses, dissertações, artigos e trabalhos publicados que somassem à revisão rigor epistemológico. Foram discutidos temas associados à teoria geossistêmica e ao planejamento urbano, principalmente nas temáticas referentes ao Plano Diretor Municipal, ao Estatuto da cidade e a Política Nacional de Proteção e Defesa Civil (PNPDEC). Os postulados de Tricart (1977) de análise morfodinâmica foram considerados para atingir o objetivo de coincidir o conhecimento da dinâmica fisiográfica com os princípios do ordenamento territorial.

Desta maneira, foram utilizadas quatro classes morfodinâmicas destacadas no mapeamento geomorfológico do estado de Minas Gerais: Fraca (Fa): Áreas caracterizadas por relevos suaves (declividades variando de 3 a 8\%). Predomínio da pedogênese sobre a morfogênese; Moderada (Mo) São áreas onde os relevos apresentam declividades que variam de 8 a $20 \%$. Existe ação do escoamento superficial do sobre o solo, mas de maneira leve, balanceando a equação da pedogênese e morfogênese; Forte (Fo): Compreende áreas marcadas por relevos entre 20 e $45 \%$ de declividade. Existe predomínio da morfogênese sobre a pedogênese, logo, a ação erosiva é expressiva nessas áreas; e Muito Forte (Mfo): São áreas onde as declividades são maiores que $45 \%$. São áreas de morfogênese ativa, queda de blocos, deslizamentos, etc.

Os bancos de dados referentes às características do mapeamento geomorfológico de Minas Gerais foram coletados nas plataformas digitais do Instituto Brasileiro de Geografia e Estatística (IBGE). A plataforma digital da Infraestrutura Estadual de Dados Espaciais de Minas Gerais (IEDE) foi consultada para aquisição de dados referentes às curvas de nível, manchas urbanas e limites municipais. Também foram coletados dados disponíveis na Infraestrutura de Dados Espaciais do Sistema Estadual de Meio Ambiente e Recursos Hídricos (IDE - SISEMA) associados à hidrografia do sul de Minas Gerais.

As bases cartográficas e os mapas temáticos foram elaborados no software desktop ArcGIS Desktop 10.5 (Laboratório de Geoprocessamento/Curso de Geografia/UNIFAL-MG). O banco de dados sobre o mapeamento geomorfológico do estado de Minas Gerais (IBGE, 2009) foi utilizado. Com a ferramenta "Clip" do software, foi recortado para a área de interesse, o arquivo vetorial dos limites municipais de Cachoeira de Minas, Pouso Alegre e Santa Rita do Sapucaí. 
Os mapas temáticos referentes às classes de declividade e hipsométrico foram construídos a partir dos dados a respeito das curvas de nível, fornecidos pelo IEDE. O arquivo vetorial sobre as curvas de nível, com equidistância de vinte metros, geradas com base nas cartas topográficos de escala 1:50.000 do próprio IBGE, do estado de Minas Gerais foi adicionado e foi feito um recorte para a área de interesse.

Com as curvas de nível do município de Cachoeira de Minas estabelecidas, foi elaborado um Modelo Digital de Elevação (MDE) com a ferramenta "TIN" do programa ArcGIS e, em seguida, transformado para arquivo raster (matriz de linhas e colunas), com tamanho do pixel de dez metros. O produto raster gerado diz respeito às elevações da área de interesse. Para o mapa de declividade, este produto é submetido à ferramenta "slope" do programa. Essa ferramenta permite a elaboração do mapa de declividades, que foi destacada em porcentagem.

A partir do banco de dados disponibilizado na plataforma digital do Departamento de Solos da Universidade Federal de Viçosa (DPS-UFV) foi digitalizado o mapa pedológico da área de estudo como complemento para as classes morfodinâmicas com bases em Tricart (1977). O mapa geológico foi digitalizado a partir dos dados disponibilizados pela Companhia de Pesquisas de Recursos Minerais sobre o mapeamento geológico do estado de Minas Gerais. Esses produtos foram utilizados como base para a análise da caracterização fisiográfica da área de estudo.

Com todos os produtos cartográficos elaborados, a base cartográfica do IBGE (2009) e as bases metodológicas propostas por Jean Tricart (1977) e SILVEIRA (2010), as análises a respeito do munícipio foram elaboradas com o norte nos postulados da organização territorial de Villaça (2005) sobre o Plano Diretor Municipal. Foi elaborada uma síntese com o intuito de agregar as informações obtidas pelas análises decorrentes da morfodinâmica (TRICART, 1977). Foi determinada a relação entre as diferentes declividades, morfologias, processos morfodinâmicos e atividades antrópicas.

\section{CARACTERIZAÇÃO DA ÁREA DE ESTUDO}

Os municípios de Pouso Alegre, Santa Rita do Sapucaí e Cachoeira de Minas (Figura 1) estão localizados no sul de Minas Gerais. Pouso Alegre possui acesso por duas importantes rodovias do estado, a BR 381 - Rodovia Fernão Dias, responsável por conectar a capital Belo Horizonte/MG a São Paulo/SP e a BR 459 - Rodovia Juscelino Kubitscheck de Oliveira, responsável por conectar o município de Poços de Caldas a cidade de Lorena/SP, facilitando o acesso à BR 116 - Presidente Dutra, que permite o acesso ao Rio de Janeiro/RJ. O município de Pouso Alegre apresenta uma área total de $543.068 \mathrm{~m}^{2}$ e uma população de 130.615 habitantes (IBGE, 2010). Já Santa Rita do Sapucaí possui aproximadamente, de acordo com o censo de 2010, 
37.754 habitantes. Apresenta uma área de $352.969 \mathrm{~m}^{2}$ e pertence à região de influência das cidades (REGIC) de Pouso Alegre

O município de Cachoeira de Minas se concentra na Microrregião de Santa Rita do Sapucaí, sul de Minas Gerais. De acordo com o censo realizado pelo IBGE (2010) a população residente é de aproximadamente 11. 034 habitantes. É válido destacar o Distrito de Itaim, que é habitado por cerca de mil pessoas.

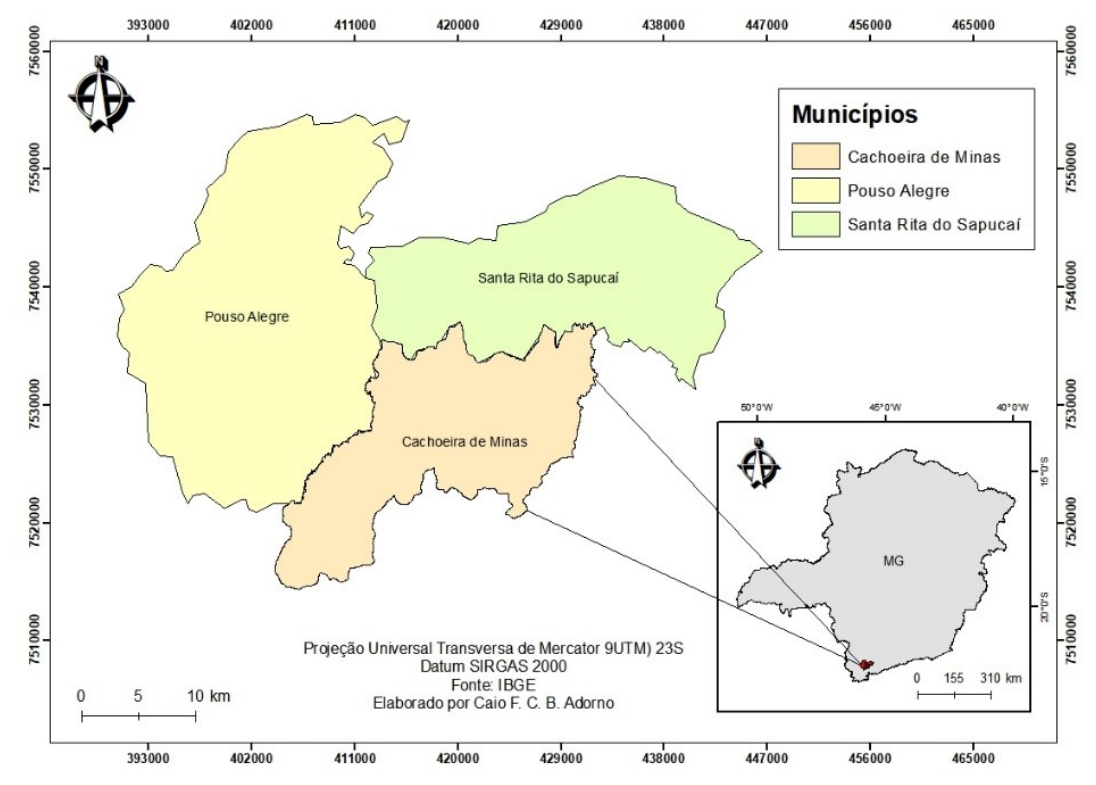

Figura 1 - Localização da área de estudo.

Fonte: Autores.

A classificação climática mais utilizada é proposta por Koeppen (1918) e foi utilizada como base para o zoneamento climático de Minas Gerais. Sá de Júnior (2009) destaca que as estações climáticas precisam ser bem definidas na classificação de Koeppen e, portanto, entende o verão de janeiro a março; outono de abril a junho; inverno entre julho e setembro; e por último a primeira de outubro a dezembro (JUNIOR, 2009).

Neste contexto, os municípios pertencem a uma zona climática delimitada pelo grande Grupo C da classificação citada, com clima temperado chuvoso e moderadamente quente. É subdividido por Cwa, temperado-úmido com inverno seco e verão úmido, e por Cwb, clima temperado úmido com inverno seco e verão moderadamente quente.

De acordo com o IDE-SISEMA (Infraestrutura de Dados Espaciais do Sistema Estadual de Meio Ambiente e Recursos Hídricos), a área de estudo se insere no bioma da Mata Atlântica. Em questões climáticas, corresponde a Zona Tropical Brasil Central de clima relativamente úmido, com temperatura média de 18 graus Celsius, variando de 3 a 4 meses de seca.

A área de estudo está inserida no trecho médio da bacia hidrográfica do rio Sapucaí, afluente do rio Grande. É predominada por floresta estacional semidecidual montana e de acordo 
com o Censo Agropecuário (IBGE, 2017) relatou que o município apresenta uma área total de 22.784, 929 hectares de estabelecimentos agrícolas. Deste montante, a maior parte é destinada à pastagem, com 13.111, 634 hectares, seguida pelas lavouras temporárias, com 4.455, 683 hectares, de milho, mandioca e café. Além destes usos, o relatório também relata 2.529, 073 hectares destinados à preservação permanente ou reserva legal de florestas (IBGE, 2017).

As classificações dos solos são importantes no momento de se elaborar planos de ocupação e uso da terra. A classificação de 2006 utilizada pela Empresa Brasileira de Pesquisa Agropecuária (EMBRAPA) foi utilizada como base para o presente trabalho. As características pedológicas do município de Cachoeira de Minas estão associadas às unidades LVd2 e LVd9 (latossolos vermelhos distróficos); LVAd1, LVAd17 e LVAd24 (latossolos vermelho-amarelo distróficos); PVAd2 (argissolos vermelho-amarelo distrófico) e PVd1 (argissolos vermelho distróficos).

A classe latossolo vermelho amarelo é caracterizada por possuir estruturas bem desenvolvidas, com camadas horizontais profundas. Na área de estudo, são distróficos, ou seja, de baixa fertilidade devido às suas limitações químicas, como o baixo teor de fósforo. Quando associado à argissolos e latossolos eutróficos de alta fertilidade, compreendem áreas de relevo fortemente ondulados, que dificultam o manejo do solo.

A caracterização geológica, realizada pela base cartográfica da Companhia de Pesquisa de Recursos Minerais (CPRM), de 2014, conta que a área de estudo pertence ao Complexo Varginha Guaxupé, composto por ortognaisses migmatíticos, piroxênios granulitos, os sedimentos terciários e quaternários citados anteriormente e diversos tonalitos

Hasui e Costa (1990) descreveram em seus trabalhos que derivam dessa área diferentes litologias associadas aos charnockitos, como os hiperstênio-granulitos, granulitos básicos e gnaisses graníticos bandados. São encontradas também algumas camadas de sedimentos areno-argilosos com fragmentos quartzíticos e lateríticos devido aos movimentos proterozoicos (ZANARDO et al., 1992).

Os aspectos geomorfológicos da área de estudo tem relação direta com a geologia e a pedologia predominantes. As ações endógenas de intensos soerguimentos e denundações expressivas são responsáveis pela gênese dos modelados homogêneos de dissecação associados a colinas e morros (LIMA et al., 2010). São frequentes os relevos mais acentuados com declividades mais altas, caracterizados por intensa ação erosiva e as paisagens associadas a intensa deposição de sedimentos, caracterizadas pela frequente presença de depósitos cenozoicos indiferenciados de idade quaternária e terciária (GASPAR JR, 2009).

As áreas caracterizadas pelo intenso transporte material, de rios hierarquicamente mais baixos e, portanto, maior capacidade de trabalho, são identificadas como vales em "V" bem encaixados em quase toda a extensão das cidades destacadas. Além dessa morfologia, também são 
frequentes os vales configurados como a letra " $U$ ", resultados da intensa ação erosiva de áreas mais altas dos planaltos, responsáveis pela deposição de materiais areno-argilosos de rochas ricas em minerais silicáticos e quartzíticos.

\section{RESULTADOS}

A análise das características físicas dos municípios confirmou que Pouso Alegre e Santa Rita do Sapucaí possuem mancha urbana em áreas naturalmente suscetível aos processos de enchente e inundação. A ocupação dessas áreas configura a vulnerabilidade (grupos sociais suscetíveis ao risco dos eventos) dos centros urbanos municipais, que estão estabelecidos nas planícies de inundação dos principais rios da área.

As planícies de inundação, ou fluviais, delimitam áreas de natureza sedimentar, logo, apresentam valores expressivos de sedimentação recente e altimetria inferior às áreas adjacentes. $\mathrm{O}$ crescimento urbano é atraído para essas regiões devido à topografia plana, que favorece a urbanização. Um dos principais problemas que surge neste contexto está associado ao fato desta morfologia comportar o leito maior dos corpos hídricos, que durante eventos extremos de chuva ou na estação predominada por valores altos de precipitação é ocupado pelas águas.

Ambos os municípios destacados apresentam um histórico de ocorrência significativo de enchentes e inundações. Foram considerados os aspectos de declividade e hipsometria das cidades para destacar a suscetibilidade e vulnerabilidade natural das mesmas. Assim como para o município de Cachoeira de Minas, que apresentou características semelhantes e mesmo padrão de evolução urbana.

\subsection{Suscetibilidade e vulnerabilidade natural de Santa Rita do Sapucaí}

O município de Santa Rita do Sapucaí apresenta mancha urbana na planície de inundação do rio Sapucaí. De acordo com os parâmetros estabelecidos por Ross (1994) para as classes de declividade, a área se enquadra no primeiro nível, com valores até 6\% (Figura 2). São áreas planas e facilitam a ocupação antrópica, já que poucas ações corretivas são requeridas. 


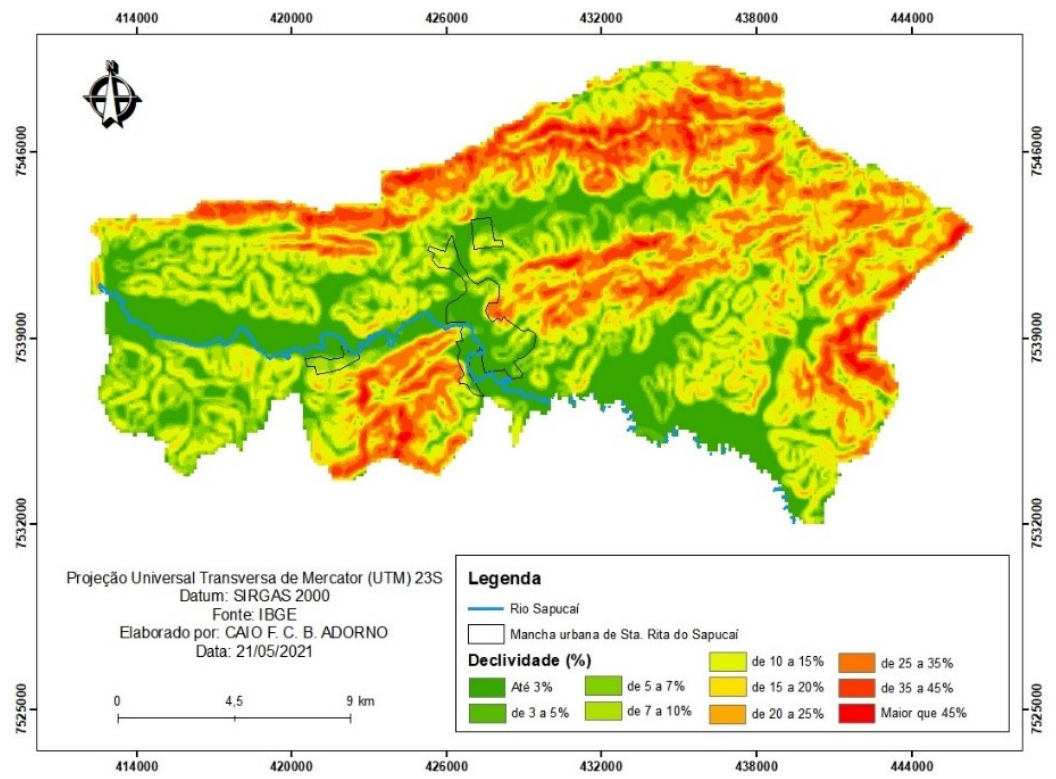

Figura 2 - Classes de declividade do município de Santa Rita do Sapucaí.

Fonte: Autor.

Os intervalos de até $20 \%$ estão associados às planícies do rio Sapucaí, adjacentes às morfologias suaves associadas às vertentes de colinas e fundos de vale. As faixas de até 30\% representam os morros com encostas suaves e os morrotes com declividades mais expressivas. Esta faixa apresenta maior grau de morfogênese. A faixa que representa as declividades muito fortes, acima de $30 \%$, associam os trechos com vertentes escarpadas dos morros. A tabela 1 traz uma síntese da relação da declividade da área da mancha urbana de Santa Rita do Sapucaí.

Tabela 1: Relação das classes de declividade com a ocupação antrópica.

\begin{tabular}{cc}
\hline Faixa de Declividade & Compartimentação morfológica e ocupação antrópica \\
\hline Até $6 \%$ & $\begin{array}{r}\text { Planície do rio Sapucaí, de declividade muito baixa. Expansão urbana } \\
\text { no leito maior do rio. }\end{array}$ \\
De $6 \%$ a $12 \%$ & $\begin{array}{r}\text { Declividade suave, fundo de vale e superfície tabular, aceitável para } \\
\text { urbanização. }\end{array}$ \\
De $12 \%$ a $20 \%$ & $\begin{array}{r}\text { Encosta de morro e relevo estrutural. Urbanização só é possível com } \\
\text { implantação de técnica. }\end{array}$ \\
De $20 \%$ a $30 \%$ & $\begin{array}{r}\text { Encosta de morros e relevos estruturais. Indicado para agricultura e ou } \\
\text { pecuária de baixa intensidade com aplicação de técnicas } \\
\text { conservacionistas. }\end{array}$ \\
Maior que $30 \%$ & $\begin{array}{r}\text { Relevos estruturais, escarpados, vales encaixado e cornijas. Aptos } \\
\text { para conservação florestal. }\end{array}$ \\
\hline
\end{tabular}

O parâmetro da declividade está diretamente relacionado com processos de transporte gravitacional, como os escoamentos e escorregamentos. Portanto, influencia diretamente nos corpos hídricos e nos processos associados a enchentes e inundação. A classificação da declividade permite a realização de um diagnóstico dos problemas associados a cada seção urbana e como as diretrizes devem ser elaboradas em cada uma delas. 
O mapa referente às classes hipsométricas do munícipio de Santa Rita do Sapucaí (Figura 3) permite a visualização da compartimentação geomorfológica predominante e da vulnerabilidade (população suscetível ao risco) natural do segmento urbano aos processos de origem geológica, enchentes e inundação.

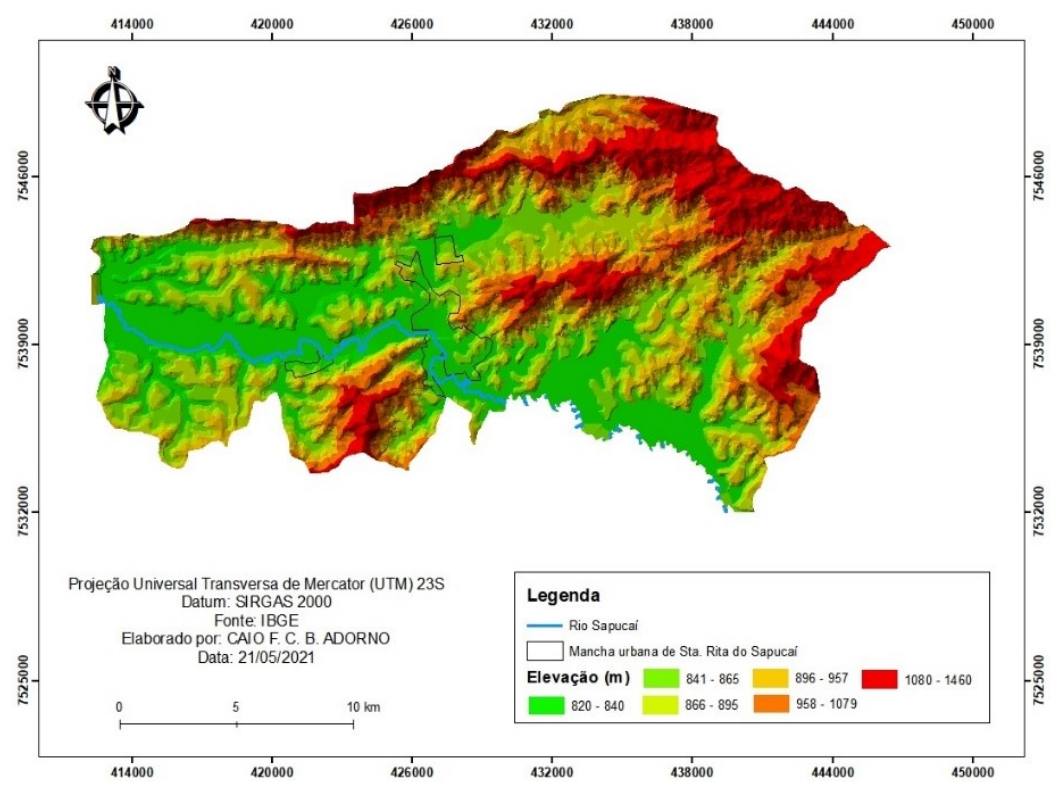

Figura 3 - Mapa altimétrico do município de Santa Rita do Sapucaí.

Percebe-se que a mancha urbana se estabelece nas áreas de baixa elevação, entre 820 e 900m. São as áreas mais planas associadas às planícies e terraços fluviais, bem como ao fundo do vale. A hipótese de que os municípios do sul de Minas Gerais apresentam padrão de desenvolvimento nas encostas dos fundos de vale e nas planícies é confirmada por esses mapas temáticos. A tabela 2 traz uma relação das faixas altimétricas com a compartimentação geomorfológica predominante.

Tabela 2: Relação das cotas altimétricas com a morfologia e morfodinâmica.

\begin{tabular}{|c|c|}
\hline Faixa altimétrica & Compartimentação Geomorfológica e processos associados \\
\hline 820 a 900 & $\begin{array}{c}\text { Domínio das planícies e terraços fluviais. Presença de colinas de } \\
\text { relevo suavemente ondulado. Predominam os processos de } \\
\text { pedogênese. }\end{array}$ \\
\hline 900 a 1030 & $\begin{array}{c}\text { Compartimentos mais elevados associados a morros de relevo } \\
\text { ondulado. Podem apresentar escoamentos lineares e movimentos } \\
\text { de massa. }\end{array}$ \\
\hline 1030 a 1240 & $\begin{array}{c}\text { São áreas serranas e compartimentos de morros delimitados por } \\
\text { cristas diversas. Podem apresentar escoamento linear forte e } \\
\text { queda de blocos. }\end{array}$ \\
\hline Maior que 1240 & $\begin{array}{l}\text { São os relevos mais elevados da área, como os paredões e } \\
\text { escarpas. Podem apresentar matacões, quedas de blocos e } \\
\text { escorregamentos de massa. }\end{array}$ \\
\hline
\end{tabular}


A análise dos parâmetros associados à geomorfologia do município de Santa Rita do Sapucaí permite a conclusão de que a mancha urbana realmente se encontra em uma área naturalmente vulnerável a processos geológicos e de enchentes e inundação (Figura 4).

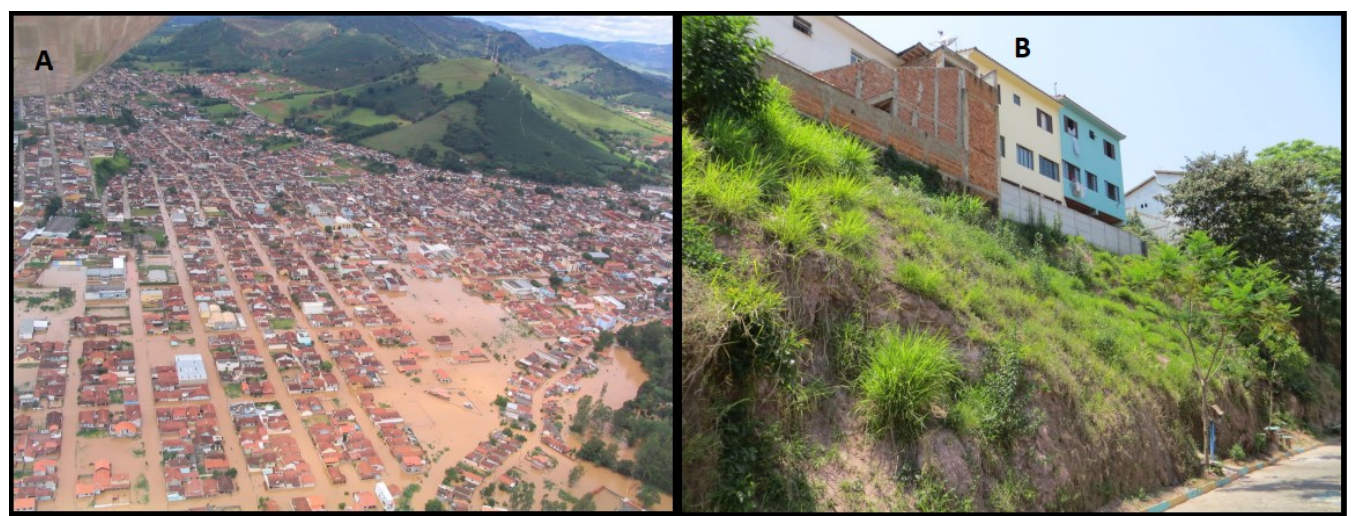

Figura 4 - A) Porção central do município de Sta. Rita do Sapucaí inundada nos anos 2000. B) Área residencial em encosta com indícios de deslizamentos no município.

Fonte: Retiradas de CPRM (2014).

\subsection{Suscetibilidade e vulnerabilidade natural de Pouso Alegre}

O município de Pouso Alegre apresente mancha urbana estabelecida na planície de inundação do rio Sapucaí-Mirim. De acordo com os parâmetros estabelecidos por Ross (1994) para as classes de declividade, a área se enquadra no primeiro nível, com valores até 6\% (Figura 5).

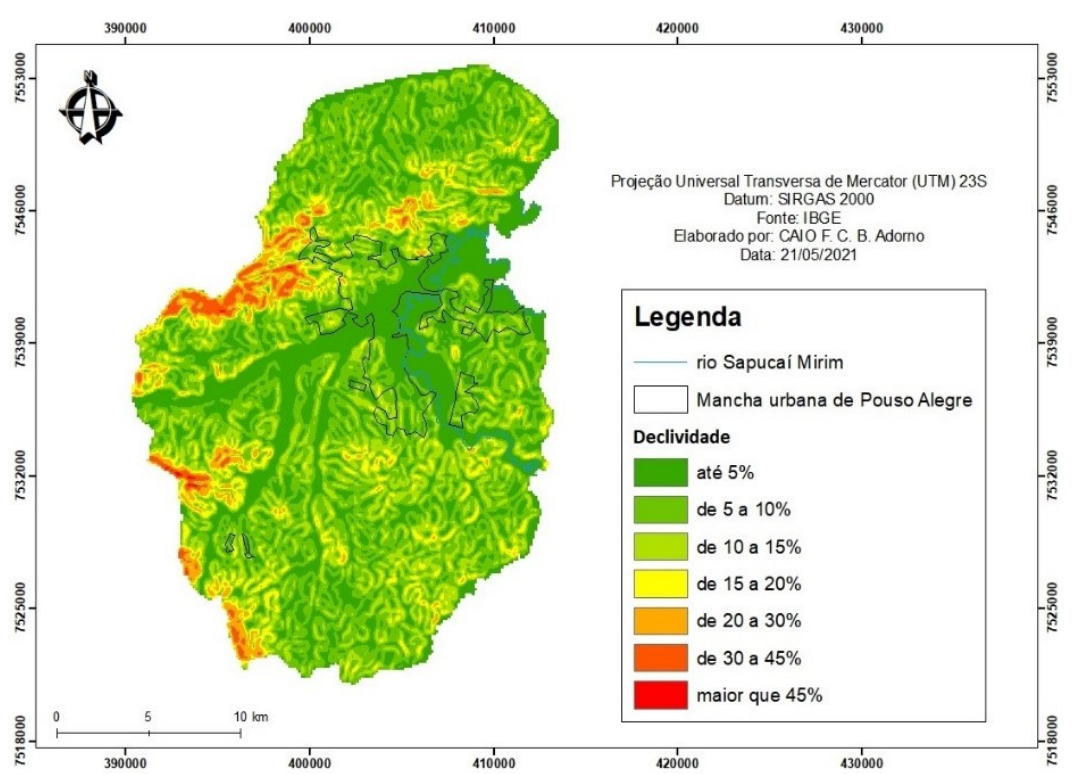

Figura 5 - Esboço das classes de declividade da mancha urbana de Pouso Alegre. Fonte: Autor.

A mancha urbana do município de Pouso Alegre, historicamente, se estabeleceu nas áreas de várzea do rio Sapucaí-Mirim. São áreas mais planas, de relevo suavemente ondulado onde predominam processos pedogenéticos. Com a crescente urbanização e a chegada dos pacotes 
tecnológicos a cidade se expandiu e os efeitos associados à natureza e ocorrência sazonal se intensificaram. A tabela 3 traz uma síntese das classes de declividade com a morfologia predominante.

Tabela 3: Relação das classes de declividade com a morfologia predominante.

\section{Faixa de Declividade}

Até $6 \%$

De $6 \%$ a $12 \%$

De $12 \%$ a $20 \%$

De $20 \%$ a $30 \%$

Maior que $30 \%$
Morfologia Predominante

Planícies e terraços fluviais do rio Sapucaí-Mirim e rio Mandu. Declividade muito baixa. Prevalecem os processos pedogenéticos. Declividade baixa; planície de inundação e leito maior excepcional. Processos de escoamento laminar são pouco expressivos. Declividade média. Nesta faixa as vertentes e as colinas favorecem o escoamento laminar das águas pluviais. A morfogênese tem força expressiva nessa faixa.

Declividade forte. Compartimentos de morros e vertentes de topo agudo. A morfogênese é bem forte nestas áreas, podendo existir até a queda de blocos e matacões.

Declividade muito forte. São as áreas mais altas de morros e montanhas de topos agudos. Predomínio total da morfogênese e provável ocorrência de quedas de blocos.

Fonte: Autor.

O relevo acidentado das áreas adjacentes à malha urbana municipal pode ser visualizado no mapa das classes altimétricas (Figura 6). Destaca-se que a mancha urbana em si está concentrada nas áreas mais baixas, logo, sujeita a receber o transporte sedimentar das áreas mais altas. Processos associados a essa configuração geomorfológica, como escoamentos superficiais, são naturalmente esperados em algumas áreas do município.

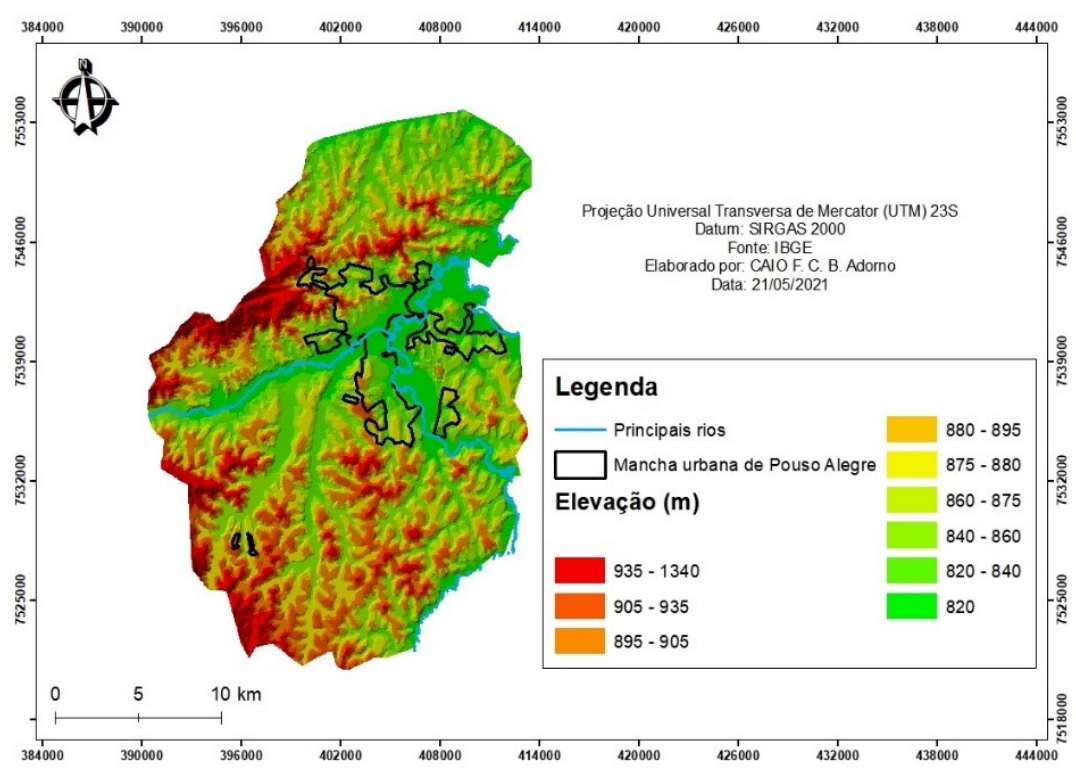

Figura 6 - Esboço altimétrico da mancha urbana de Pouso Alegre.

O mapa hipsométrico ilustra a localização da mancha urbana em uma área naturalmente vulnerável aos processos de enchentes e inundação (Figura 7). São áreas suscetíveis a esses 
processos, mas a existência de grupos sociais nestas áreas configura a vulnerabilidade dos mesmos. É preciso destacar que a recorrência sazonal das chuvas é quem dita o comportamento hidrológico dos corpos d'água.
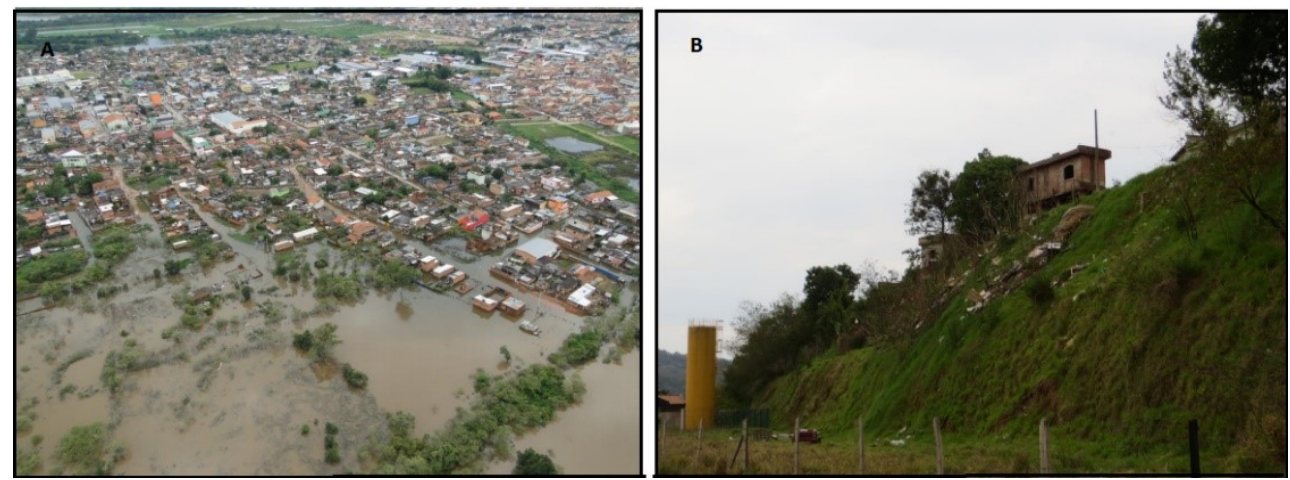

Figura 7 - A) inundação em 2011 na área urbana de Pouso Alegre. B) Encosta íngreme ocupada em Pouso Alegre. Fonte: Retiradas de CPRM (2014).

Pouso Alegre e Santa Rita do Sapucaí são municípios que já apresentam o histórico de ocorrência de eventos de ordem hídrica. O que tem acontecido é que a urbanização, com a construção de lotes em áreas previamente florestais, tem aumentado o escoamento e diminuído a infiltração (CHRISTOFOLETTI, 1999). Neste contexto, a articulação da comunidade científica com os aparatos legais vigentes deve se integrar às políticas de ordenamento territorial para a mitigação destes problemas.

\subsection{Suscetibilidade e vulnerabilidade natural de Cachoeira de Minas}

Esta seção objetiva discorrer sobre os processos relacionados a enchentes e inundação no contexto da mancha urbana de Cachoeira de Minas. O município não apresenta, assim como Pouso Alegre e Santa Rita do Sapucaí, histórico de ocorrência desses processos. Porém configura o padrão discutido no presente trabalho sobre a expansão urbana em áreas suscetíveis a esses processos, com a ocupação dos fundos de vale e das encostas.

Em um primeiro momento, o planejamento físico-territorial da cidade de Cachoeira de Minas remete a interpretação da caracterização fisiográfica do limite municipal. O centro urbano, por exemplo, é localizado em áreas planas dos fundos de vale, adjacentes às vertentes de morros de morfologia ondulada e suavemente ondulada (Figura 8). 


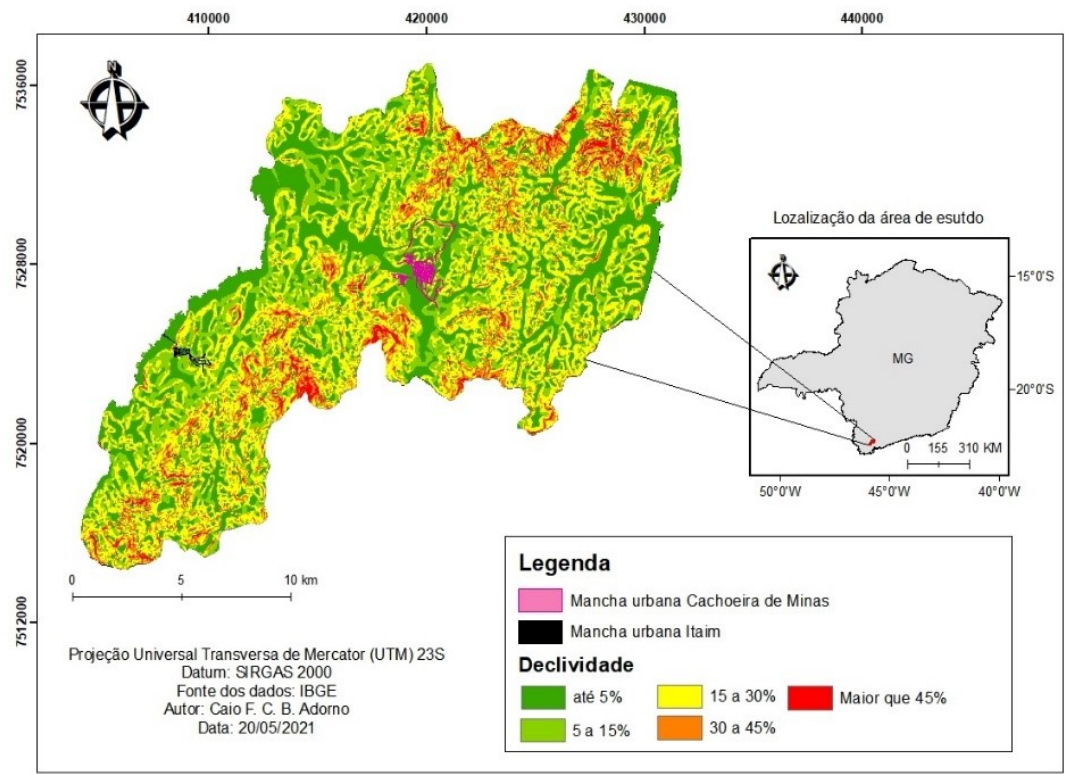

Figura 8: Esboço das classes de declividade da mancha urbana de Cachoeira de Minas.

Fonte: Autor

Estabelecido que a declividade é definida como o ângulo de inclinação da superfície do terreno, fica evidente que os processos erosivos e de enchentes e inundação estão diretamente associados. Pelo esboço cartográfico das classes de declividade, a mancha urbana municipal se estabeleceu em uma área baixa, que tende a se desenvolver nas encostas das vertentes.

Historicamente a ocupação do município está associada às planícies fluviais do rio Sapucaí-Mirim. São áreas de natureza plana e sedimentar, atrativas para a ocupação antrópica. Por se localizarem em cotas altimétricas inferiores (Figura 9) as áreas circundantes, tendem a receber aporte expressivo de material sedimentar.

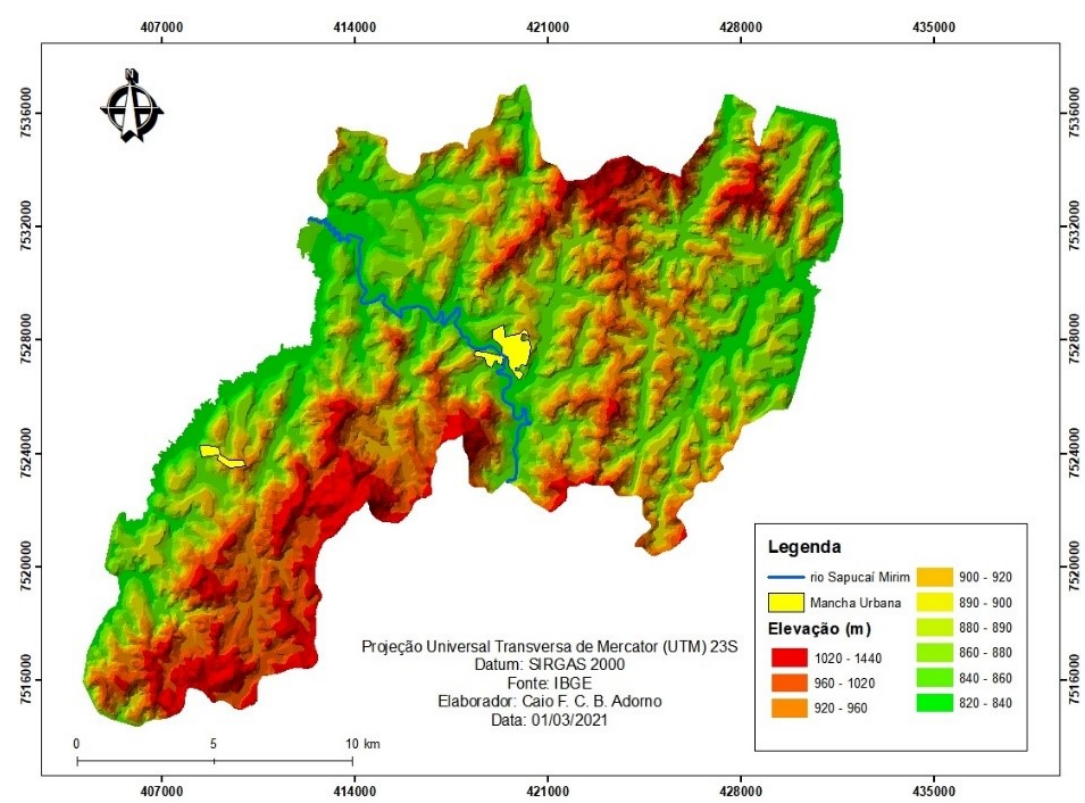

Figura 9 - Esboço altimétrico da mancha urbana de Cachoeira de Minas. 
A análise do mapa hipsométrico destaca que o centro urbano municipal está inserido na planície do rio Sapucaí-Mirim, que também pode ser denominada área de ocupação do leito maior, logo, áreas que irão ser ocupadas pelo corpo hídrico no período das cheias. Do ponto de vista físico, o perímetro de várzea do rio deveria ser preservado para manutenção da qualidade das águas, fauna e flora locais, mas, como o próprio esboço altimétrico ilustra, é uma área intensamente explorada.

Mais ao norte da mancha urbana existem áreas mais elevadas, com cotas que chegam até 1000 metros. A urbanização nesses locais deve ser controlada para que sejam evitados problemas de ordem física e geológica do relevo. Além da necessidade de fiscalização da lei vigente.

A tendência das cidades é sempre de expansão (VILLAÇA, 2001). A tabela 5 traz uma síntese da relação entre a morfologia predominante no município de Cachoeira de Minas com o padrão de ocupação e a morfogênese associada.

Tabela 5: Relação das classes de declividade, morfologia e ocupação antrópica.

\begin{tabular}{|c|c|c|c|c|}
\hline Declividade & $\begin{array}{c}\text { Morfologia } \\
\text { Predominante }\end{array}$ & $\begin{array}{c}\text { Processos } \\
\text { Associados } \\
\end{array}$ & $\begin{array}{l}\text { Ocupação } \\
\text { Antrópica }\end{array}$ & $\begin{array}{c}\text { Classes } \\
\text { Morfodinâmicas }\end{array}$ \\
\hline Até $5 \%$ & $\begin{array}{l}\text { Planícies aluviais; } \\
\text { terraços fluviais; } \\
\text { fundos de vale. }\end{array}$ & $\begin{array}{c}\text { Entre } 0 \text { e } 3 \% \text { o } \\
\text { terreno é plano ou } \\
\text { quase plano, } \\
\text { predomínio da } \\
\text { pedogênese. De } 4 \text { a } \\
5 \% \text { pode existir o } \\
\text { início do escoamento } \\
\text { difuso e laminar. }\end{array}$ & $\begin{array}{l}\text { Urbanização; malha } \\
\text { viária, agricultura } \\
\text { mecanizada. }\end{array}$ & $\begin{array}{c}\text { Fraca (FA): } \\
\text { Predomínio da } \\
\text { pedogênese sobre a } \\
\text { morfogênese. }\end{array}$ \\
\hline De 5 a $15 \%$ & $\begin{array}{c}\text { Encostas de morros. } \\
\text { Estruturas de relevo } \\
\text { ondulado. }\end{array}$ & $\begin{array}{l}\text { Escoamento laminar; } \\
\text { processos de } \\
\text { voçorocamento e } \\
\text { movimentos de } \\
\text { massa; balanço entre } \\
\text { morfogênese e } \\
\text { pedogênese. }\end{array}$ & $\begin{array}{l}\text { Área utilizada para o } \\
\text { cultivo do café e } \\
\text { agricultura } \\
\text { mecanizada; pouco } \\
\text { indicada para } \\
\text { ocupação antrópica. }\end{array}$ & $\begin{array}{c}\text { Moderado (Mo): } \\
\text { Existe a } \\
\text { morfogênese, mas de } \\
\text { maneira balanceada. }\end{array}$ \\
\hline De 15 a $30 \%$ & $\begin{array}{l}\text { Encostas e escarpas } \\
\text { de falha; relevo } \\
\text { fortemente ondulado. }\end{array}$ & $\begin{array}{l}\text { Erosão linear muito } \\
\text { forte; } \\
\text { escorregamentos } \\
\text { rotacionais. }\end{array}$ & $\begin{array}{l}\text { Pecuária; não é } \\
\text { indicado para uso } \\
\text { urbano. }\end{array}$ & $\begin{array}{c}\text { Forte (Fo): } \\
\text { Predomínio da } \\
\text { morfogênese e } \\
\text { destruição dos solos. }\end{array}$ \\
\hline De 30 a $45 \%$ & $\begin{array}{l}\text { Relevos estruturais e } \\
\text { montanhosos. }\end{array}$ & $\begin{array}{l}\text { Escorregamentos } \\
\text { rotacionais e } \\
\text { translacionais; queda } \\
\text { de blocos e erosão } \\
\text { linear. }\end{array}$ & $\begin{array}{c}\text { Preservação } \\
\text { Florestal. }\end{array}$ & $\begin{array}{c}\text { Forte (Fo): } \\
\text { Predomínio da } \\
\text { morfogênese e } \\
\text { destruição dos solos. }\end{array}$ \\
\hline Maior que $45 \%$ & $\begin{array}{l}\text { Paredões e relevos } \\
\text { montanhosos. }\end{array}$ & $\begin{array}{l}\text { Escorregamentos } \\
\text { rotacionais e } \\
\text { translacionais, } \\
\text { solifluxão e queda de } \\
\text { blocos. }\end{array}$ & $\begin{array}{l}\text { Preservação } \\
\text { Florestal. }\end{array}$ & $\begin{array}{l}\text { Muito forte (Mfo): } \\
\text { Expressa o maior } \\
\text { domínio da } \\
\text { morfogênese e ação } \\
\text { intempérica. }\end{array}$ \\
\hline
\end{tabular}

O modelo guia para uma análise morfodinâmica de processos associados a riscos geológicos, enchentes e inundação precisa da integração dos dados do diagnóstico ambiental da área de análise. Outro fator que precisa ser destacado é a aplicação da lei vigente. No caso de desastres ambientais, a lei 12.608/2012, que dispõe sobre o Sistema Nacional de Proteção e Defesa Civil, 
discorre a criação de uma Coordenadoria Municipal de Proteção e Defesa Civil - COMPDEC. Esse órgão seria responsável pelo planejamento, articulação e coordenação de ações que interessam ao município.

A execução e aplicação coerente da COMPDEC emergem de um cenário onde a realidade municipal é conhecida, tanto nos aspectos físicos quanto sociais. A elaboração do modelo de análise do meio físico para a definição de diretrizes necessita de análises de campo, com a delimitação de limites de análise, para o zoneamento em escalas de maior detalhamento.

\section{CONCLUSÃO}

Os processos morfodinâmicos, por exemplo, associados aos centros urbanos e loteamos com planos de ocupação precisam ser identificados no plano diretor municipal. O prognóstico ambiental de uma área precisa ser considerado na pauta do ordenamento territorial. A dinâmica de ocupação antrópica nos cenários destacados na pesquisa, nos municípios de Santa Rita do Sapucaí e Pouso Alegre configuram suscetibilidade natural a adversidades ambientais associadas a enchentes e inundação, logo, as diretrizes precisam ser restritivas e corretivas para algumas áreas.

O município de Cachoeira de Minas segue a mesma lógica de expansão que ambos os municípios destacados no parágrafo anterior, assim como a maioria das cidades no contexto regional do sul de Minas Gerais. A elaboração de estudos para oferecer suporte técnico-cientifico em diretrizes dos planos diretores parte do reflexo negativo que a expansão urbana possui quando iniciada em áreas inadequadas.

Nesta narrativa, os diferentes tipos de uso e ocupação do solo, relacionados às diferentes morfologias, apresentam processos e repostas singulares para cada caso. $\mathrm{O}$ trabalho identificou as classes morfodinâmicas do município de Cachoeira de Minas na busca de ilustrar como o conhecimento do meio físico é essencial ao ordenamento territorial. Fornecer uma síntese dos problemas associados a ocupação dessas áreas, na tentativa de subsidiar diretrizes ao Plano Diretor Municipal, é uma das propostas geossistêmicas que pode auxilar o planejamento urbano.

É preciso ressaltar que estudos interdisciplinares no contexto do diagnostico ambiental são essenciais na discussão do Plano Diretor Municipal. O conhecimento do meio físico precisa ser contemplado nas diretrizes do ordenamento territorial. Negligenciar a dinâmica natural em ambientes antrópicos pode resultar em efeitos catastróficos tanto para a natureza, quanto para a sociedade.

O sul de Minas Gerais apresenta diversos municípios com o mesmo padrão de desenvolvimento e que estão suscetíveis a uma série de problemas de ordem natural. A elaboração de um modelo de análise do meio físico que subsidie diretrizes nos planos diretores municipais é uma das propostas que o artigo busca destacar. A criação de cartas geotécnicas associadas a 
enchentes e inundação, ou a problemas de natureza geológica também se enquadram nessa narrativa. A busca por metodologias que assegurem a qualidade de vida e o direito ao meio ambiente em estado de equilíbrio precisa ser contemplada no exercício do ordenamento territorial.

\section{REFERÊNCIAS}

AB'SABER, A. N. Um conceito de geomorfologia a serviço das pesquisas sobre o quaternário. Geomorfologia, São Paulo, n. 18, p. 1-23, 1969.

AMORIM FILHO, O. B. A Formação do Conceito de Paisagem Geográfica: os Fundamentos Clássicos. In: OLIVEIRA, L.; MACHADO, L. M. C. P. Paisagens. Rio Claro: UNESP, 1998.

BARREIROS, A. M. Da paisagem como objeto da Geografia: repasse teórico e sugestão metodológica. 2017, 116 f. Tese (Doutorado em Geografia) - Faculdade de Filosofia, Letras e Ciências Humanas, Universidade de São Paulo, São Paulo, 2017.

BERTRAND, G. Paisagem e Geografia Física global: esboço metodológico. Caderno de Ciências da Terra, São Paulo, n. 13, p. 1-27, 1972.

CASTELLO, L. A percepção em análises ambientais: o projeto MAB/Unesco em Porto Alegre. In: DEL RIO, V; OLIVEIRA, O. (Org.). Percepção ambiental: A experiência brasileira. São Paulo: Studio Nobel, 1999.

CHRISTOFOLETTI, A. Modelagem de sistemas ambientais. São Paulo: Edgard Blücher, 1999. $256 \mathrm{p}$.

GUERRA, A. J. T.; MARÇAL, M. S. Geomofologia Ambiental. Rio de Janeiro: Bertrand Brasil, 2006. 190p.

MONTEIRO, C. A. F. Geossistemas: a história de uma procura. São Paulo: Contexto, 2001. 127p.

NASCIMENTO, M. A; CARVALHO, P. F. Pensando o planejamento ambiental para cidades pequenas: o caso de Perdões - MG. In: MENDES, A. A. LOMBARDO, M. A. Paisagens geográficas e desenvolvimento territorial. Rio Claro: PPGUnesp, 2005, p. 27- 44.

NEVES, C. E. O uso do Geossistema no Brasil: Legados Estrangeiros, Panorama Analítico e Contribuições para uma Perspectiva Complexa. 2019. 400 f. Tese (Doutorado em Geografia) Universidade Estadual Paulista, Presidente Prudente, 2019.

NUNES, J. O. R. Práxis geográfica e suas conjunções. 2014. 150 f. Tese (Livre Docência em Geografia) - Faculdade de Ciência e Tecnologia, Universidade Estadual Paulista, Presidente Prudente, 2014.

NUNES, J. O. R. Uma contribuição metodológica ao estudo da dinâmica da paisagem aplicada a escolha de áreas para a construção de aterro sanitário em Presidente Prudente - SP. 2002. 230 f. Tese (Doutorado em Geografia) - Faculdade de Ciências e Tecnologia, Universidade Estadual Paulista, Presidente Prudente, 2002.

PEREZ FILHO, A., QUARESMA, C. C.; RODRIGUES, T. R. I. Ação antrópica como agente transformador da organização espacial em bacias hidrográficas. Diez años de cambios en el Mundo, 
en la Geografía y en las Ciencias Sociales, 1999-2008. In: COLOQUIO INTERNACIONAL DE GEOGRÍTICA. 10., Barcelona. Anais... Barcelona, 2008.

ROSS, J. L. S. Geomorfologia: ambiente e planejamento. São Paulo: Contexto, 1990. 85p.

SANTOS, C. Cartografia ambiental e planejamento territorial urbano. Patrimônio: Lazer \& Turismo, v. 6, n. 7, p. 40-74, 2009.

SANTOS, M. A natureza do Espaço. São Paulo: HUCITEC, 1996. 394p.

SCHWEIGERT, L. R. Plano Diretor e sustentabilidade ambiental da cidade. 2007. $143 \mathrm{f}$. Dissertação (Mestrado em Arquitetura e Urbanismo) - Universidade Presbiteriana Mackenzie, São Paulo, 2007.

SOTCHAVA, V. B. O estudo dos Geossistemas - métodos em questão. Instituto de Geografia, São Paulo, v. 16, p. 1-51, 1976.

SOUZA, L. A.; SOBREIRA, F. G. Guia para elaboração de cartas geotécnicas de aptidão a urbanização frente aos desastres naturais: Estudo de caso de Ouro Preto. Ouro Preto: UFOP, 2014. $68 \mathrm{p}$.

SOUZA, M. A. Meio ambiente e Desenvolvimento Sustentável. As metáforas do capitalismo. Cronos, Natal, v. 10, n. 2, p. 101-117, 2009.

SUERTEGARAY, D. M. A. O atual e as tendências do ensino e da pesquisa em Geografia no Brasil. Revista do Departamento de Geografia (USP), São Paulo, v. 16, p. 38-45, 2005.

SUERTEGARAY, D. M. A.; MORETTI, E. C. Considerações sobre o eixo temático Natureza no contexto dos Encontros Nacionais de Geógrafos (Brasil) 2008-2012. Terra Livre, v. 2, n. 42, 2014.

TROPPMAIR, H. Geossistemas e geossistemas paulistas. Rio Claro: UNESP, 2000. 259p.

TROPPMAIR, H.; GALINA, M. H. Geossistemas (Geosystems). Mercator, Fortaleza, v. 5, n. 10, p. 79-90, 2008.

VILLAÇA, F. Uma contribuição para a história do planejamento urbano no Brasil. Processo de Urbanização no Brasil, São Paulo: EdUSP, 2004. 76p.

VINHA, T. M. Elementos para Elaboração de SIG no Planejamento e Gestão para Expansão Urbana em Álvares Machado - SP. 2011. 160 f. Dissertação (Mestrado em Geografia) Universidade Estadual Paulista, Presidente Prudente, 2011.

WULF, A. A invenção da natureza: a vida e as descobertas de Alexandre von Humboldt. São Paulo: Planeta, 2016. 600p. 